\title{
Ligand Exchange Reaction of Ferrocene with Substituted Benzenes
}

\author{
Yutaka Okada*, Yoshiharu Kato \\ Department of Applied Chemistry, Ritsumeikan University, Kusatsu, Japan \\ Email: *ygvictor@sk.ritsumei.ac.jp
}

How to cite this paper: Okada, Y. and Kato, Y. (2022) Ligand Exchange Reaction of Ferrocene with Substituted Benzenes. International Journal of Organic Chemistry, 12, 1-10.

https://doi.org/10.4236/ijoc.2022.121001

Received: January 15, 2022

Accepted: March 5, 2022

Published: March 8, 2022

Copyright $\odot 2022$ by author(s) and Scientific Research Publishing Inc. This work is licensed under the Creative Commons Attribution International License (CC BY 4.0).

http://creativecommons.org/licenses/by/4.0/

\begin{abstract}
Ligand exchange reaction is one of the typical reactions of ferrocene. In this paper, ligand exchange reactions were carried out between ferrocene and various substituted benzenes using aluminum chloride catalysis. The product yields of the reactions with alkanoyl- and alkoxybenzenes were low because of the coordination of aluminum chloride to the oxygens of the benzene substituents. Comparing the reactions using $o$ - and $p$-dimethoxybenzene, the former was revealed to be less reactive; this is likely due to the deviation of the $\pi$-electrons of its benzene ring being larger.
\end{abstract}

\section{Keywords}

Ferrocene, Ligand Exchange Reaction, Substituted Benzenes

\section{Introduction}

Ferrocene is an organoiron compound comprising an iron atom sandwiched between two cyclopentadienyl $(\mathrm{Cp})$ rings, and was accidentally synthesized by two independent research groups via different strategies in the early 1950s [1] [2].

Ferrocene is commonly used in ligand exchange reactions, which were discovered by Nesmeyanov et al. [3]. These are reactions in which a Cp ring of ferrocene exchanges with an aromatic ring, such as benzene, in the presence of a Lewis acid catalyst, such as aluminum chloride; the product is often isolated as a stable $\mathrm{PF}_{6}$ salt (Scheme 1). In this reaction, aluminum chloride abstracts one ferrocene $\mathrm{Cp}$ ring from a position above the molecule and along the direction of the $\mathrm{Cp}$-iron bond axis, causing ferrocene to decompose into two fragments; the iron atom is then coordinated by the other aromatic compound (Scheme 2) [4].

There have been many studies on the ligand exchange reactions of ferrocene 


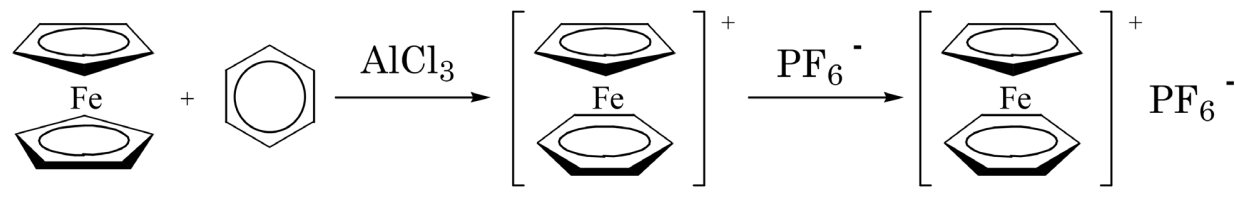

Scheme 1. The ligand exchange reaction between ferrocene and benzene.

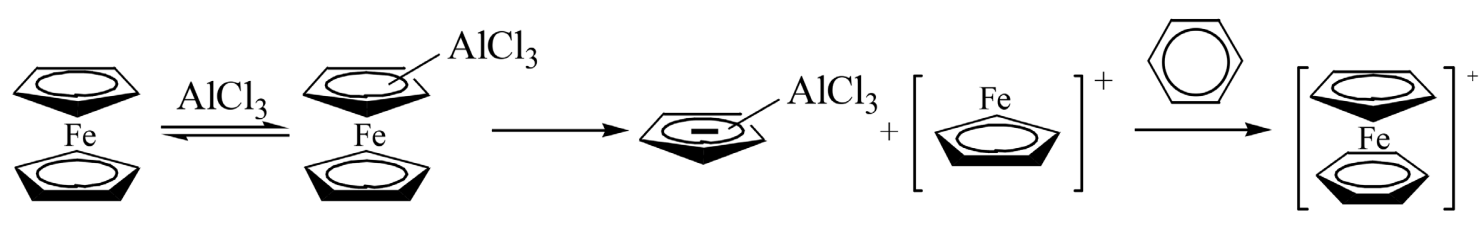

Scheme 2. The reaction mechanism of the ligand exchange reaction between ferrocene and benzene.

[5]. For instance, with regard to the electric effect of the substituent on the reaction of the 1,1'-disubstituted ferrocenes with benzenes, the reactivity increased by the introduction of methyl groups [6]. We have reported the reactions between alkylferrocenes and benzene-based hydrocarbons [7], as well as reactions between ferrocene and heterocyclic compounds [8]. Ferrocene has also reportedly undergone ligand exchange with polyalkyl-substituted benzenes, where higher reactivity was noted when the benzene substituents were asymmetrical than when they were symmetrical [9].

In this study, we conducted ligand exchange reactions between ferrocene and benzene derivatives bearing alkyl, alkanoyl, alkoxyl, or chloro groups, and also studied the effects of these substituents on the reactivity.

\section{Experimental}

\subsection{Measurements of Ligand Exchange Reaction}

The ligand exchange reactions catalyzed by aluminum chloride were carried out in 1,2-dichloroethane or decalin. A typical procedure is as followed. The ferrocenes $(1.2 \mathrm{mmol})$ and benzenes $(1.2 \mathrm{mmol})$ were dissolved in 1,2-dichloroethane $\left(12 \mathrm{~cm}^{3}\right)$. Anhydrous aluminum (III) chloride $(0.16 \mathrm{~g}, 1.2 \mathrm{mmol})$ was then added to the solution. The solution was placed in an oil bath, and heated. The reaction time was 120 minutes. The ligand exchange products were analyzed as $\mathrm{PF}_{6}$ salts by ${ }^{1} \mathrm{H}-\mathrm{NMR}$ and HPLC [9]. A commercially available reagent was used with no further purification.

\subsection{Measurement Apparatus}

The ${ }^{1} \mathrm{H}-\mathrm{NMR}$ spectra were measured in acetone- $d_{6}$ at room temperature using a JEOL ECS-400 spectrometer. The NMR data are shown in Table 1.

\section{Results and Discussion}

\subsection{The Ligand Exchange Reaction with Alkylbenzenes}

Ligand exchange reactions between ferrocene and alkylbenzenes afforded the exchange products in high yields in all the cases (Table 2); the reactivities of 
Table 1. ${ }^{1} \mathrm{H}-\mathrm{NMR}$ chemical shifts (ppm) of the ligand exchange products in acetone- $d_{6}$.
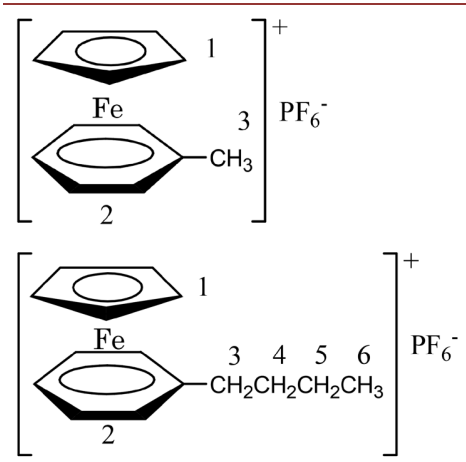

5.19

$(5 \mathrm{H})$

\section{2}

6.43

$(5 \mathrm{H})$

3
2.88
$(2 \mathrm{H})$

4

1.66

(2H)

1.42

(2H)

0.94

$(3 \mathrm{H})$
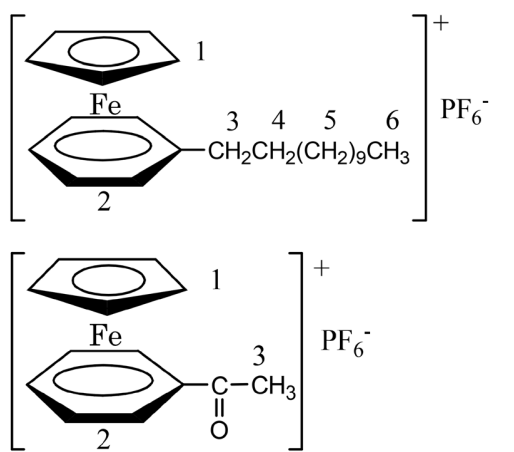

$\begin{array}{lll}1 & 2 & 3 \\ 5.18 & 6.41 & 2.47 \\ (5 \mathrm{H}) & (5 \mathrm{H}) & (3 \mathrm{H})\end{array}$

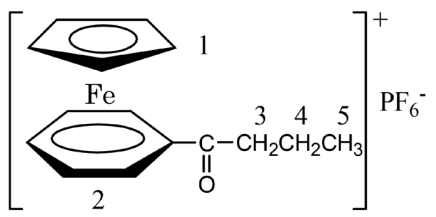

1

5.19

(5H)

2

6.43

3

2.87

4

1.68

5

(5H)

(2H)

(2H)

$(3 \mathrm{H})$

1

5.14

(5H)

\section{2}

6.35

(4H)

$$
3
$$

2.60

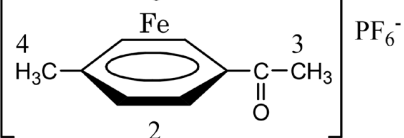

\section{1}
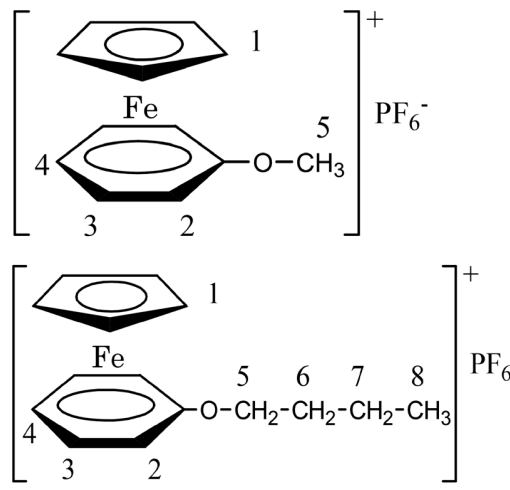

4

(2H)

(3H)

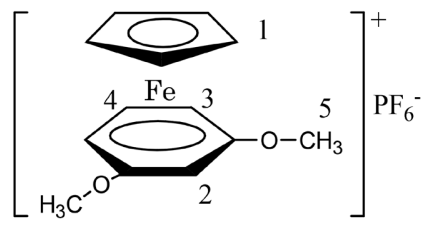

123

5.15

6.31

6.39

4

6.20

5

(5H)

(1H)

(2H)

(1H)

(6H) 


\section{Continued}

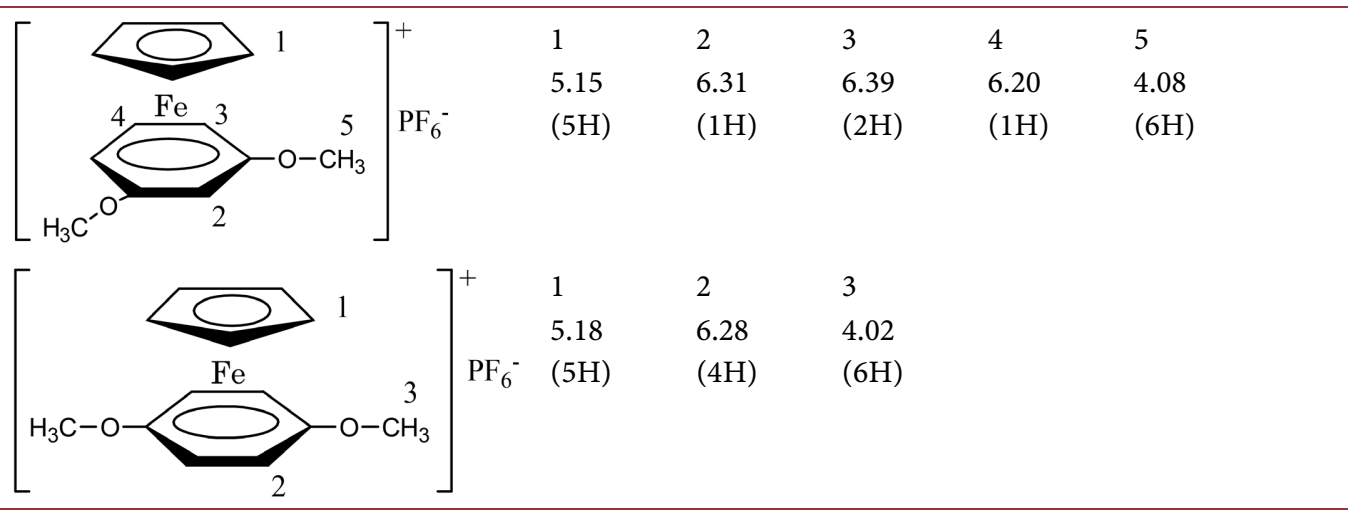

Table 2. Yields of ligand exchange reactions of ferrocene with alkylbenzenes.

\begin{tabular}{|c|c|c|c|c|}
\hline $\mathrm{Fe}$ & $\mathrm{R}=\mathrm{CH}_{3}$ & $\begin{array}{c}\mathrm{AlCl}_{3} \\
\mathrm{PF}_{6}^{-} \\
{ }_{4}^{-} \mathrm{H}_{9}, n-\mathrm{C}\end{array}$ & $L$ & ]$^{+} \mathrm{PF}_{6}^{-}$ \\
\hline Arene & Fc:arene: $\mathrm{AlCl}_{3}$ & Solvent & Temperature $/{ }^{\circ} \mathrm{C}$ & Yield/\% \\
\hline Toluene & $1: 1: 1$ & $\mathrm{C}_{2} \mathrm{H}_{4} \mathrm{Cl}_{2}$ & 80 & 22.3 \\
\hline Toluene & $1: 1: 2$ & $\mathrm{C}_{2} \mathrm{H}_{4} \mathrm{Cl}_{2}$ & 80 & 38.9 \\
\hline Toluene & $1: 1: 1$ & $\mathrm{C}_{10} \mathrm{H}_{18}$ & 130 & 8.8 \\
\hline Toluene & $1: 1: 2$ & $\mathrm{C}_{10} \mathrm{H}_{18}$ & 130 & 12.1 \\
\hline Butylbenzene & $1: 1: 1$ & $\mathrm{C}_{2} \mathrm{H}_{4} \mathrm{Cl}_{2}$ & 80 & 21.9 \\
\hline Butylbenzene & $1: 1: 2$ & $\mathrm{C}_{2} \mathrm{H}_{4} \mathrm{Cl}_{2}$ & 80 & 37.6 \\
\hline Butylbenzene & $1: 1: 1$ & $\mathrm{C}_{10} \mathrm{H}_{18}$ & 130 & 9.9 \\
\hline Butylbenzene & $1: 1: 2$ & $\mathrm{C}_{10} \mathrm{H}_{18}$ & 130 & 19.9 \\
\hline Dodecylbenzene & $1: 1: 1$ & $\mathrm{C}_{2} \mathrm{H}_{4} \mathrm{Cl}_{2}$ & 80 & 15.3 \\
\hline Dodecylbenzene & $1: 1: 2$ & $\mathrm{C}_{2} \mathrm{H}_{4} \mathrm{Cl}_{2}$ & 80 & 35.0 \\
\hline Dodecylbenzene & $1: 1: 1$ & $\mathrm{C}_{10} \mathrm{H}_{18}$ & 130 & 10.6 \\
\hline Dodecylbenzene & $1: 1: 2$ & $\mathrm{C}_{10} \mathrm{H}_{18}$ & 130 & 12.8 \\
\hline
\end{tabular}

these reactions were determined based on these product yields.

The yields obtained from alkylbenzenes were higher than that obtained from benzene because the aromatic ring of an alkylbenzene has higher $\pi$-electron density than benzene due to the electron-donating effect of the alkyl group [10]. Notably, upon varying the length of the alkyl chain, no difference in yield was observed. We had expected the coordination to be less likely to occur with longer linear chains due to steric effects, but the results did not show negative steric effects. 


\subsection{The Ligand Exchange Reaction with Alkanoylbenzenes}

It was found that the reactivities of the alkanoylbenzenes are lower than those of the aforementioned alkylbenzenes when reacted with ferrocene. This is because alkanoyl groups are electron-withdrawing, making the $\pi$-electron densities of alkanoylbenzene rings low. Therefore, alkanoylbenzenes are less likely to coordinate to the $\mathrm{CpFe}$ fragment compared to alkylbenzenes. Another contributor to the low reactivities of alkanoylbenzenes could be the fact that aluminum chloride coordinates with the carbonyl oxygen atoms. We confirmed this by comparing the reactivities of ligand exchange reactions of ferrocene with alkylbenzenes and alkanoylbenzenes using $\mathrm{Fc}$ :arene: $\mathrm{AlCl}_{3}$ ratios of 1:1:1 and 1:1:2. Upon doubling the amount of aluminum chloride, the reactivities of the exchange reactions with alkylbenzenes increased no more than 2-fold, while those of the reactions with alkanoylbenzenes increased 4- to 6-fold. This is because even if some aluminum chloride was coordinated to the alkanoylbenzene carbonyl group, excess aluminum chloride was present for use in the reaction.

Therefore, for ligand exchange with alkanoylbenzenes, ferrocene and aluminum chloride were first mixed to ensure aluminum chloride coordinated with ferrocene; the alkanoylbenzene reagent was then added to the solution (method 2). Other reaction conditions (Table 3), viz. temperature and solvent, were then evaluated. We found that using 1,2-dichloroethane as the solvent at a reaction temperature of $80^{\circ} \mathrm{C}$ gave no product, regardless of the alkanoylbenzene used. Contrastingly, when decalin was used as the solvent at a reaction temperature of $130^{\circ} \mathrm{C}$, the target products could be obtained.

Table 3. Yields of ligand exchange reactions of ferrocene with alkanoylbenzenes.

\begin{tabular}{|c|c|c|c|c|}
\hline $\mathrm{Fe}$ & $\begin{array}{l}\mathbb{\mathrm { O }} \\
\mathrm{R}=\mathrm{CH}_{3}, r\end{array}$ & $\begin{array}{l}\underset{\mathrm{PF}_{6}^{-}}{\stackrel{\mathrm{AlCl}_{3}}{\longrightarrow}} \\
\mathrm{C}_{3} \mathrm{H}_{7}, n-\mathrm{C}_{1}\end{array}$ & $\overline{\mathrm{H}}_{23}$ & ]$^{+} \mathrm{PF}_{6}^{-}$ \\
\hline Arene & Fc:arene: $\mathrm{AlCl}_{3}$ & Solvent & Temperature $/{ }^{\circ} \mathrm{C}$ & Yield/\% \\
\hline Acetophenone & $1: 1: 1(\operatorname{method} 1)$ & $\mathrm{C}_{2} \mathrm{H}_{4} \mathrm{Cl}_{2}$ & 80 & 0 \\
\hline Acetophenone & $1: 1: 2(\operatorname{method} 1)$ & $\mathrm{C}_{2} \mathrm{H}_{4} \mathrm{Cl}_{2}$ & 80 & 2.0 \\
\hline Acetophenone & $1: 1: 1(\operatorname{method} 1)$ & $\mathrm{C}_{10} \mathrm{H}_{18}$ & 130 & 1.2 \\
\hline Acetophenone & $1: 1: 2($ method 1$)$ & $\mathrm{C}_{10} \mathrm{H}_{18}$ & 130 & 8.0 \\
\hline Acetophenone & $1: 1: 1(\operatorname{method} 2)$ & $\mathrm{C}_{10} \mathrm{H}_{18}$ & 130 & 9.0 \\
\hline Acetophenone & $1: 1: 2(\operatorname{method} 2)$ & $\mathrm{C}_{10} \mathrm{H}_{18}$ & 130 & 24.4 \\
\hline Acetophenone & $1: 1: 2(\operatorname{method} 2)$ & $\mathrm{C}_{10} \mathrm{H}_{18}$ & 80 & 13.0 \\
\hline Butyroylbenzene & 1:1:1 (method 1$)$ & $\mathrm{C}_{2} \mathrm{H}_{4} \mathrm{Cl}_{2}$ & 80 & 0 \\
\hline Butyroylbenzene & $1: 1: 2(\operatorname{method} 1)$ & $\mathrm{C}_{2} \mathrm{H}_{4} \mathrm{Cl}_{2}$ & 80 & 1.1 \\
\hline
\end{tabular}




\begin{tabular}{ccccc} 
Continued & & & \\
\hline Butyroylbenzene & $1: 1: 1(\operatorname{method} 1)$ & $\mathrm{C}_{10} \mathrm{H}_{18}$ & 130 & 1.0 \\
Butyroylbenzene & $1: 1: 2(\operatorname{method} 1)$ & $\mathrm{C}_{10} \mathrm{H}_{18}$ & 130 & 7.6 \\
Butyroylbenzene & $1: 1: 1(\operatorname{method} 2)$ & $\mathrm{C}_{10} \mathrm{H}_{18}$ & 130 & 6.6 \\
Butyroylbenzene & $1: 1: 2(\operatorname{method} 2)$ & $\mathrm{C}_{10} \mathrm{H}_{18}$ & 130 & 14.8 \\
Dodecanoylbenzene & $1: 1: 1(\operatorname{method} 1)$ & $\mathrm{C}_{2} \mathrm{H}_{4} \mathrm{Cl}_{2}$ & 80 & 0 \\
Dodecanoylbenzene & $1: 1: 2(\operatorname{method} 1)$ & $\mathrm{C}_{2} \mathrm{H}_{4} \mathrm{Cl}_{2}$ & 80 & 0 \\
Dodecanoylbenzene & $1: 1: 1(\operatorname{method} 1)$ & $\mathrm{C}_{10} \mathrm{H}_{18}$ & 130 & 0 \\
Dodecanoylbenzene & $1: 1: 2(\operatorname{method} 1)$ & $\mathrm{C}_{10} \mathrm{H}_{18}$ & 130 & 0 \\
Dodecanoylbenzene & $1: 1: 1(\operatorname{method} 2)$ & $\mathrm{C}_{10} \mathrm{H}_{18}$ & 130 & 0 \\
Dodecanoylbenzene & $1: 1: 2(\operatorname{method} 2)$ & $\mathrm{C}_{10} \mathrm{H}_{18}$ & 130 & 0 \\
$p$-Methylacetophenone & $1: 1: 2(\operatorname{method} 1)$ & $\mathrm{C}_{2} \mathrm{H}_{4} \mathrm{Cl}_{2}$ & 80 & 0 \\
$p$-Methylacetophenone & $1: 1: 2(\operatorname{method} 1)$ & $\mathrm{C}_{10} \mathrm{H}_{18}$ & 130 & 0 \\
$p$-Methylacetophenone & $1: 1: 1(\operatorname{method} 2)$ & $\mathrm{C}_{10} \mathrm{H}_{18}$ & 130 & 2.5 \\
\hline
\end{tabular}

Evaluating the alkanoylbenzene scope revealed that products could be obtained with acetophenone and butyroylbenzene, which both bear a short alkyl group; however, no product was attained using dodecanoylbenzene, which bears a long alkyl group. These results are substantial because there have only been a few reports on ligand exchange reactions of ferrocene with alkanoylbenzenes.

\subsection{The Ligand Exchange Reaction with Alkoxybenzenes}

Ferrocene was reacted with anisole, butoxybenzene, and dimethoxybenzene (ortho, para, and meta) (Table 4). Products were obtained when anisole and butoxybenzene were used regardless of solvent and temperature, but the highest yields were attained in both cases using 1,2-dichloroethane as the solvent and a Fc:arene: $\mathrm{AlCl}_{3}$ ratio of 1:1:2. For reactions with both anisole and butoxybenzene, products were obtained in higher yields when a $\mathrm{Fc}:$ arene: $\mathrm{AlCl}_{3}$ ratio of 1:1:2 was used over a ratio of 1:1:1; this was also the case with alkyl- and alkanoylbenzenes. This is because, like the carbonyl oxygens of alkanoylbenzenes, the unshared electron pair on the oxygen atoms of the alkoxy groups were attacked by aluminum chloride. Moreover, anisole provided higher product yields than butoxybenzene, which is likely owing to the carbon chain of the former being shorter; this was also noted with alkanoylbenzenes.

The ligand exchange reaction of ferrocene with $o$-dimethoxybenzene did not give the desired product, but those with $m$ - and $p$-dimethoxybenzene did (Table 4). Similar to the reactions with monoalkoxybenzenes, those with $m$ - and $p$-dimethoxybenzene gave higher product yields when the amount of aluminum chloride was doubled. Furthermore, the reactivity of $m$-dimethoxybenzene was inferior to that of $p$-dimethoxybenzene; thus, the reactivities are ordered as follows: 
Table 4. Yields of ligand exchange reactions of ferrocene with alkoxybenzenes.

\begin{tabular}{|c|c|c|c|c|}
\hline+ & $\mathrm{R}=\mathrm{CH}_{3}, n-\mathrm{C}_{4}$ & $\frac{\mathrm{AlCl}_{3}}{\mathrm{PF}_{6}^{-}}$ & {[} & ]$_{\mathrm{PF}_{6}}^{+}$ \\
\hline Arene & Fc:arene: $\mathrm{AlCl}_{3}$ & Solvent & Temperature $/{ }^{\circ} \mathrm{C}$ & Yield/\% \\
\hline Anisole & $1: 1: 1$ & $\mathrm{C}_{2} \mathrm{H}_{4} \mathrm{Cl}_{2}$ & 80 & 1.1 \\
\hline Anisole & $1: 1: 2$ & $\mathrm{C}_{2} \mathrm{H}_{4} \mathrm{Cl}_{2}$ & 80 & 29.4 \\
\hline Anisole & $1: 1: 1$ & $\mathrm{C}_{10} \mathrm{H}_{18}$ & 130 & 2.6 \\
\hline Anisole & $1: 1: 2$ & $\mathrm{C}_{10} \mathrm{H}_{18}$ & 130 & 3.6 \\
\hline Butoxylbenzene & $1: 1: 1$ & $\mathrm{C}_{2} \mathrm{H}_{4} \mathrm{Cl}_{2}$ & 80 & 1.5 \\
\hline Butoxylbenzene & $1: 1: 2$ & $\mathrm{C}_{2} \mathrm{H}_{4} \mathrm{Cl}_{2}$ & 80 & 17.5 \\
\hline Butoxylbenzene & $1: 1: 1$ & $\mathrm{C}_{10} \mathrm{H}_{18}$ & 130 & 4.6 \\
\hline Butoxylbenzene & $1: 1: 2$ & $\mathrm{C}_{10} \mathrm{H}_{18}$ & 130 & 1.2 \\
\hline$o$-Dimethoxybenzene & $1: 1: 1$ & $\mathrm{C}_{2} \mathrm{H}_{4} \mathrm{Cl}_{2}$ & 80 & 0 \\
\hline$o$-Dimethoxybenzene & $1: 1: 2$ & $\mathrm{C}_{2} \mathrm{H}_{4} \mathrm{Cl}_{2}$ & 80 & 0 \\
\hline$o$-Dimethoxybenzene & $1: 1: 1$ & $\mathrm{C}_{10} \mathrm{H}_{18}$ & 130 & 0 \\
\hline$o$-Dimethoxybenzene & $1: 1: 2$ & $\mathrm{C}_{10} \mathrm{H}_{18}$ & 130 & 0 \\
\hline$m$-Dimethoxybenzene & $1: 1: 1$ & $\mathrm{C}_{2} \mathrm{H}_{4} \mathrm{Cl}_{2}$ & 80 & 14.4 \\
\hline$m$-Dimethoxybenzene & $1: 1: 2$ & $\mathrm{C}_{2} \mathrm{H}_{4} \mathrm{Cl}_{2}$ & 80 & 21.8 \\
\hline$m$-Dimethoxybenzene & $1: 1: 1$ & $\mathrm{C}_{10} \mathrm{H}_{18}$ & 130 & 2.4 \\
\hline$m$-Dimethoxybenzene & $1: 1: 2$ & $\mathrm{C}_{10} \mathrm{H}_{18}$ & 130 & 0 \\
\hline
\end{tabular}

$o$-derivative $<<m$-derivative $<p$-derivative

Contrastingly, it has been reported that the ligand exchange reaction of ferrocene with $o$-xylene yields more product than that with $p$-xylene; this is likely because the positions of the substituents on the benzene ring of $\mathrm{X}$ are deviated, which causes steric hindrance when the benzene ring is coordinated to the $\mathrm{CpFe}$ moiety [9]. This difference from the case of $o$ - and $p$-dimethoxybenzene could be ascribed to the methoxy group being a stronger electron donor than the methyl group. Thus, the electron density on the benzene ring of $\mathrm{X}$ is more deviated than that of the benzene ring of $\mathrm{Y}$, making the coordination of $\mathrm{Z}$ to the $\mathrm{CpFe}$ moiety less likely to occur. As such, the benzene ring of $\mathrm{X}$ no longer acts as a pentahapto $\left(\eta^{6}\right)$ ligand. Meanwhile, the substituents of the $p$-derivative are present at symmetrical positions, which makes its electron density deviation small and its coordination to the $\mathrm{CpFe}$ moiety possible. A similar example can be found in the previously reported ligand exchange reactions of ferrocene with heteroaromatic 
compounds like pyrrole, pyrazole, and imidazole [8]; the $\pi$-electron densities of these aromatic rings are deviated, leading to their low reactivities.

\subsection{The Ligand Exchange Reaction with Mixed Aromatic Compounds}

Ferrocene also underwent ligand exchange with toluene-anisole, toluene- $o$-dimethoxybenzene, and toluene-p-dimethoxybenzene mixtures. In all cases, a Fc:arene 1:arene 2: $\mathrm{AlCl}_{3}$ ratio of 2:1:1:4 was used, and the main products were the result of ligand exchange between ferrocene and toluene (Table 5).

The toluene ligand exchange product was obtained in a higher yield when mixed with $o$-dimethoxybenzene than when mixed with $p$-dimethoxybenzene. This is because $o$-dimethoxybenzene has two methoxy groups sterically closer to each other, while those of $p$-dimethoxybenzene are on opposite sides of the ring. Therefore, the $o$-derivative would be less likely to attack the methoxy group of aluminum chloride. This makes $o$-dimethoxybenzene suitable for ferrocene ligand exchange because it can tolerate the relatively large amount of aluminum chloride required for extracting the $\mathrm{Cp}$ ring of ferrocene.

Moreover, the product yield was lower for toluene- $p$-dimethoxybenzene mixture than that for the toluene-anisole mixture because $p$-dimethoxybenzene has two methoxy units and anisole only has one.

\subsection{The Ligand Exchange Reaction with Chlorobenzenes}

The ligand exchange reactions between ferrocene and $o$-dichlorobenzene or $p$ dichlorobenzene were also carried out. In both cases, no ligand exchange could be confirmed, just as no ligand exchange was obtained with $p$-diacetylbenzene, which also has electron-withdrawing substituents. Similar to alkanoylbenzenes, dichlorobenzenes likely do not undergo ligand exchange with ferrocene because the electron densities of their benzene rings decrease owing to the electron-withdrawing chloro groups; thus, it could not coordinate to the CpFe component.

\section{Conclusions}

Ligand exchange reactions were carried out between ferrocene and various benzene derivatives bearing alkyl, alkanoyl, alkoxyl, or chloro groups. The target ligand exchange products were obtained in all the cases except for those using dichlorobenzenes. The yields of the reactions with alkanoyl- and alkoxybenzenes were low, which was ascribed to aluminum chloride coordinating to the oxygen

Table 5. Yields of ligand exchange reactions of ferrocene with alkylbenzenes.

\begin{tabular}{ccccc}
\hline Arene 1/arene 2 & Fc:arene 1:arene 2: $\mathrm{AlCl}_{3}$ & Solvent & Temperature/ ${ }^{\circ} \mathrm{C}$ & Yield $^{\mathrm{a}} \%$ \\
\hline Toluene/anisole & $2: 1: 1: 4$ & $\mathrm{C}_{2} \mathrm{H}_{4} \mathrm{Cl}_{2}$ & 80 & 33.3 \\
Toluene/o-dimethoxybenzene & $2: 1: 1: 4$ & $\mathrm{C}_{2} \mathrm{H}_{4} \mathrm{Cl}_{2}$ & 80 & 37.8 \\
Toluene/ $p$-dimethoxybenzene & $2: 1: 1: 4$ & $\mathrm{C}_{2} \mathrm{H}_{4} \mathrm{Cl}_{2}$ & 80 & 10.6 \\
\hline
\end{tabular}

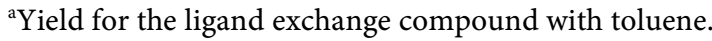


atoms of the substituents.

Ferrocene ligand exchange using dimethoxybenzene derivatives was compared to that using xylene derivatives, where the $o$-derivative of xylene and the $p$-derivative of dimethoxybenzene were the most reactive. The steric hindrance in $p$ xylene at the time of coordination was large, leading to its lower reactivity compared to $o$-xylene. Meanwhile, $o$-dimethoxybenzene exhibited larger deviation in the $\pi$-electron density of its benzene ring than $p$-dimethoxybenzene, making it less reactive.

The reactions in the presence of the alkoxybenzenes and toluene did not give the ligand exchange product with the alkoxybenzenes, but the product with toluene. This result would support that aluminum chloride coordinates to the oxygen atoms of the substituents

The alkyl chain lengths of alkylbenzenes did not affect their reactivities in ferrocene ligand exchange, but alkanoyl- and alkoxybenzenes bearing long chains gave no ligand exchange products. As such, the differences in ligand exchange reaction behavior among alkyl-, alkanoyl-, and alkoxybenzenes require further investigation.

\section{Conflicts of Interest}

The authors declare no conflicts of interest regarding the publication of this paper.

\section{References}

[1] Kealy, T.J. and Pauson, P.L. (1951) A New Type of Organo-Iron Compound. Nature, 168, 1039-1040. https://doi.org/10.1038/1681039b0

[2] Miller, S.A., Tebboth, J.A. and Tremaine, J.F. (1952) Dicyclopentadienyliron. Journal of Chemical Society, 632-635. https://doi.org/10.1039/jr9520000632

[3] Nesmeyanov, A.N., Vol'kenau, N.A. and Isaeva, L.S. (1963) The Interaction of Ferrocene and Its Derivatives with Aromatic Compounds. Tetrahedron Letters, 4, 1725-1729. https://doi.org/10.1016/S0040-4039(01)90903-7

[4] Astruc, D. and Dabard, R. (1976) Contribution to the Study of Metallocenes: XXIV. on the Mechanism of Ligand Exchange and Complexation by Aluminum Chloride of Ferrocene and Its Alkylated and Acylated Derivatives. Journal of Organometallic Chemistry, 111, 339-347. https://doi.org/10.1016/S0022-328X(00)98142-7

[5] Abd-El-Aziz, A.S. and Bernardin, S. (2000) Synthesis and Reactivity of Arenes Coordinated to Cyclopentadienyliron Cations. Coordination Chemistry Reviews, 203, 219-267. https://doi.org/10.1016/S0010-8545(99)00182-4

[6] Astruc, D. and Dabrd, R. (1976) Organo-Iron Complexes of Aromatic Compounds. Applications in Synthesis. Tetrahedron, 39, 4027-4095. https://doi.org/10.1016/S0040-4020(01)88627-0

[7] Hayashi, T., Okada, Y. and Shimizu, S. (1996) Studies on Ferrocene Derivatives. Part 12. Substituent Effects for the Disproportionation, Synproportionation and Ligand Exchange Reactions of $t$-Butylferrocenes. Transition Metal Chemistry, 21, 418-422. https://doi.org/10.1007/BF00140783

[8] Okada, Y., Huruya, H. and Imori, Y. (2015) Ligand Exchange Reaction of Ferrocene 
with Heterocycles. International Journal of Organic Chemistry, 5, 282-290.

https://doi.org/10.4236/ijoc.2015.54028

[9] Okada, Y., Yoshigami, Y. and Hayashi, T. (2003) Studies on Ferrocene Derivatives. Part XVI. Steric Effects on the Ligand Exchange Reactions of Alkylferrocenes. Transition Metal Chemistry, 28, 794-799. https://doi.org/10.1023/A:1026006314010

[10] Vela, J., Vaddadi, S., Cundari, T.R., Smith, J.M., Gregory, E.A., Lachicotte, R.J., Flaschenriem, C.J. and Holland, P.L. (2004) Reversible Beta-Hydrogen Elimination of Three-Coordinate Iron(II) Alkyl Complexes: Mechanistic and Thermodynamic Studies. Organometallics, 23, 5226-5239. https://doi.org/10.1021/om049415+ 